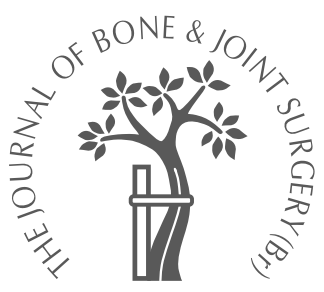

K. Fujii, S. Katoh, K. Sairyo, T. Ikata, N. Yasui

From the University of Tokushima, Japan

K. Fujii, MD

S. Katoh, MD, Associate

Professor

K. Sairyo, MD, Assistant

Professor

T. Ikata, MD, Professor

Emeritus

N. Yasui, MD, Professor and Chairman

Department of Orthopedics School of Medicine, The University of Tokushima,

3-18-15 Kuramoto-cho,

Tokushima 770-8503, Japan.

Correspondence should be sent to Dr S. Katoh.

C2004 British Editorial Society of Bone and Joint Surgery

doi:10.1302/0301-620X.86B2.

$14339 \$ 2.00$

$J$ Bone Joint Surg [Br]

2004;86-B:225-31.

Received 20 March 2003;

Accepted after revision

18 July 2003

\title{
Union of defects in the pars interarticularis of the lumbar spine in children and adolescents
}

\author{
THE RADIOLOGICAL OUTCOME AFTER \\ CONSERVATIVE TREATMENT
}

\begin{abstract}
Lumbar spondylolysis can heal with conservative treatment, but few attempts have been made to identify factors which may affect union of the defects in the pars. We have evaluated, retrospectively, the effects of prognostic variables on bony union of pars defects in 134 young patients less than 18 years of age with 239 defects of the pars who had been treated conservatively. All patients were evaluated by CT scans when first seen and more than six months later at follow-up.

The results showed that the spinal level and the stage of the defects were the predominant factors. The site of the defects in the pars, the presence or development of spondylolisthesis, the condition of the contralateral pars, the degree of lumbar lordosis and the degree of lumbar inclination all significantly affected union.
\end{abstract}

Spondylolysis is seen frequently in growing children. Wiltse, Widell and Jackson ${ }^{1}$ demonstrated that in most patients isthmic spondylolysis was due to a fatigue fracture of the pars interarticularis as a result of repeated trauma, and many others have supported this view. ${ }^{2-10}$ Most affected children and adolescents can participate in sports even if their defects in the pars have not healed, but they are at an increased risk of developing endplate lesions and subsequent vertebral deformities, including wedging or slipping of the involved vertebra.,6,11-15 These complications can be avoided by obtaining bony union of the defects. A number of studies have reported successful union, but have indicated that the response to conservative treatment varies considerably. ${ }^{5,6,11,16}$ Although the aetiology of the pars defects has been studied, only a few attempts have been made to identify the factors such as age, the type of defect, timely and correct bracing, the presence of spina bifida, lumbar lordosis, and other aetiological variables which influence the union of the defects. ${ }^{10,17-19}$ No significantly associated factors have been identified. ${ }^{11,16}$

In a previous study, we found a significant correlation between the stage of the defect and successful bony union, ${ }^{6}$ which, as determined by plain radiographs, occurred in $73 \%$ of early stage defects, $39 \%$ of progressive defects and in none in the terminal stage. Plain radiographs cannot detect the defect accurately because the angle or site of the defect in the pars inter- articularis is not consistent. Further analysis of patients with defects was necessary to accurately determine the prognostic factors for successful bony union.

\section{Patients and Methods}

We have reviewed retrospectively the clinical records and radiological investigations of 134 patients diagnosed with lumbar spondylolysis. All were examined by plain radiographs and CT scans when first seen and when followed up more than six months later. Their age at the first presentation ranged from seven to 17 years (mean, 13.8). There were 109 boys and 25 girls. The sports in which they were active are listed in Table I. The mean age when they had started a sport was $9.4 \pm 2.3$ years for the 115 patients whose age was recorded (Table I). They played sport for 1.5 to 5.3 hours each day and on two to seven days each week (Table I). They also played at least one game a week during the season.

Defects were present at L4 in 20 patients and at L5 in 114. Bilateral defects were observed in 105 patients and unilateral defects in 29. In total, we studied 239 defects. We included patients who were followed for less than two years. The mean duration of followup of 121 patients ranged from one to 9.8 years (average, 3.4). There were 13 patients who were followed-up for less than 12 months. They had no disabling low back pain or any evidence of union of the defects and, subsequently, did not require treatment. 
Table I. The types of sports played, the age at which the patients started playing and the number of hours per week spent playing for the 134 children with pars defects of the lumbar spine

\begin{tabular}{lc}
\hline Sports & $\begin{array}{c}\text { Number of } \\
\text { patients }\end{array}$ \\
\hline Soccer & 30 \\
Baseball & 26 \\
Basketball & 15 \\
Volleyball & 10 \\
Athletics & 9 \\
Judo & 5 \\
Tennis & 4 \\
Kendo & 4 \\
Others & 28 \\
None & 3 \\
Total & 134 \\
Age when started sport & \\
$\quad<5$ years & 1 \\
5 to $<10$ years & 69 \\
10 to $<15$ years & 41 \\
15 years or older & 4 \\
Total (19 not recorded) & 115 \\
Duration of sport/week & \\
$<10$ hours & 26 \\
10 to $<20$ hours & 510 \\
20 to $<30$ hours & 50 \\
30 to 40 hours & 31 \\
Total $(24$ not recorded) & \\
\hline
\end{tabular}

CT images were obtained using the reverse-gantry angles on the plane parallel to the pars interarticularis. ${ }^{6}$ The images were taken at 1200 to 2200 window width and 150 to 220 window level with slices $2 \mathrm{~mm}$ thick and at $2 \mathrm{~mm}$ intervals.

We classified pars defects into an early, progressive or terminal stage based on plain radiographs according to previously reported criteria, ${ }^{6}$ which were also used to analyse CT findings (Fig. 1). ${ }^{20}$ An early defect was defined as a fissure in the pars. In the progressive stage, the defect was still narrow, but its edge was round. If the defect was wide and sclerosis was observed, it was considered to be in the terminal stage. We assessed that union of the defect had occurred when the gap had disappeared and trabeculation through the pars was observed. In patients with bony union, callus formation was usually not detected on plain radiographs and only fuzziness of the defect was observed at the three-month follow-up. By six months the defect had disappeared on plain radiographs, but trabeculation was not complete on CT. It took nearly 12 months for complete union to be confirmed by CT.

The maturity of the lumbar spine was classified into the cartilaginous, apophyseal and epiphyseal stage according to our previously reported criteria, based on the appearance of the secondary ossification centre of the cranio-anterior edge of the third lumbar vertebral body on plain lateral radiographs. ${ }^{14}$

Treatment. Patients were asked to discontinue their sporting activities and to wear a Damen corset for at least three months. They were encouraged to undertake isometric exercises to maintain and strengthen the trunk muscles. Once pain had subsided, they were gradually mobilised and carried out isotonic exercises of the trunk muscles. At threemonth follow-up, they were advised not to play sport for another three months if the radiographs showed signs of union of the defects. If the defects became worse, or there was no sign of union, patients were allowed to go back to their previous activities provided that their pain had decreased and their trunk muscles were stronger. When
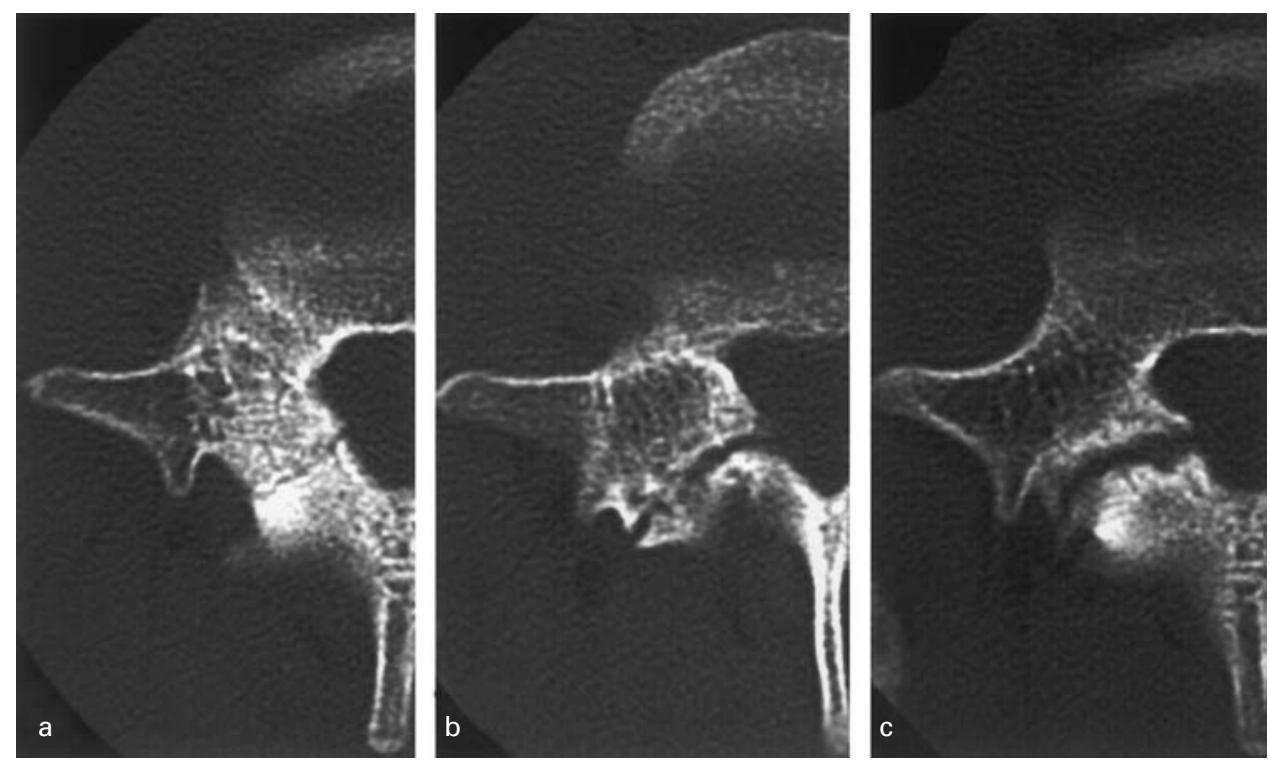

Fig. 1

Representative CT images of pars defects in a) the early stage, b) the progressive stage and c) the terminal stage. 
Table II. Local factors which may affect union following conservative treatment of pars defects of the lumbar spine in children

\begin{tabular}{|c|c|}
\hline \multicolumn{2}{|l|}{ Local factors } \\
\hline Stage of the pars defect ${ }^{1 *}$ & The number with union/total (\%) \\
\hline Early & $31 / 50 \quad(62.0)$ \\
\hline Progressive & 9/103 (8.7) \\
\hline Terminal & $0 / 86 \quad(0.0)$ \\
\hline Stage of the contralateral pars defect** & Union/total (\%) \\
\hline No defect & $12 / 29 \quad(41.4)$ \\
\hline Early & $18 / 32 \quad$ (56.3) \\
\hline Progressive & $10 / 97 \quad(10.3)$ \\
\hline Terminal & $0 / 81 \quad(0.0)$ \\
\hline Vertebral levelt & Union/total (\%) \\
\hline L4 & $22 / 35 \quad(62.9)$ \\
\hline L5 & $18 / 204$ (8.8) \\
\hline Spondylolisthesis $\ddagger$ & Union/total (\%) \\
\hline$\geq 5 \%$ & $3 / 65 \quad(4.6)$ \\
\hline$<5 \%$ & $37 / 174(21.3)$ \\
\hline Distance of early and progressive stage defects from the posterior margin $\neq \ddagger$ & (mean \pm SD) of the vertebral body \\
\hline Union & $0.53 \pm 0.15$ \\
\hline Nonunion & $0.55 \pm 0.12$ \\
\hline Angle of early and progressive stage defects $\ddagger \ddagger$ & (mean $\pm S D)$ in degrees \\
\hline Union & $14.5 \pm 11.8$ \\
\hline Nonunion & $15.8 \pm 15.0$ \\
\hline \multicolumn{2}{|c|}{$\begin{array}{l}{ }^{*} \text { early } v \text { progressive or terminal, } \mathrm{p}<0.0001 \\
{ }^{* *} \text { no defect } v \text { progressive or terminal, } \mathrm{p}=0.0004, \mathrm{p}<0.0001 ; \text { early } v \text { progressive or terminal, } \mathrm{p}<0.0001 \\
\dagger \mathrm{p}<0.0001\end{array}$} \\
\hline $\begin{array}{l}\neq p=0.0016 \\
\ddagger \ddagger \text { only early and progressive stage defects are included }\end{array}$ & \\
\hline
\end{tabular}
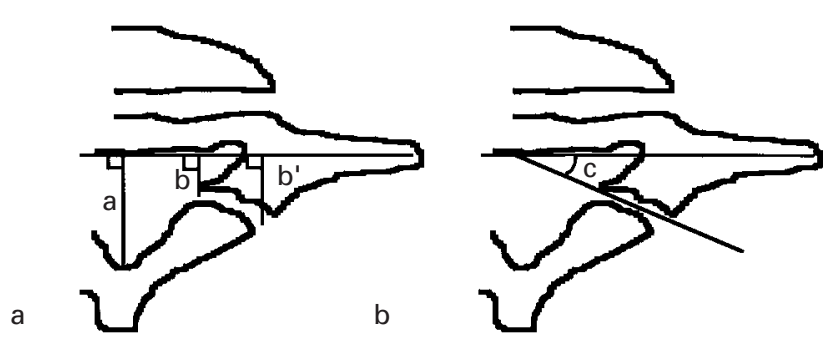

Fig. 2

Schematic drawings of measurement of pars defects on CT images obtained in a plane parallel to the pars interarticularis. a) The distance of the defect from the posterior margin of the vertebral body was calculated using the following formula: distance $=\left(b+b^{\prime}\right) / 2 a$ and $\left.b\right)$ the angle of the defect to the posterior margin of the vertebral body (c) was measured.

union of the defects was confirmed on radiographs or by CT, they were advised to start sport wearing a lumbosacral support to restrict lumbar extension. ${ }^{6}$

Factors examined. Factors that might influence union of the pars defect were examined. They were divided into groups local to the pars interarticularis and the lumbosacral spine and those which were systemic. Local factors (Table II) included the vertebral level of the defect, the stage of the defect on CT at the first presentation, the presence of spondylolisthesis with more than $5 \%$ slip, the distance of the defect from the posterior margin of the vertebral body and the angle of the defect to the posterior margin of the vertebral body (Fig. 2). ${ }^{20}$ The lumbosacral factors (Table
Table III. Lumbosacral factors which may affect the union of pars defects of the lumbar spine in children

\begin{tabular}{|c|c|}
\hline Lumbosacral factors & \\
\hline Spina bifida & The number with union/total (\%) \\
\hline With & $5 / 40 \quad(12.5)$ \\
\hline Without & $35 / 199 \quad$ (17.6) \\
\hline Lumbar index (L5) & $($ mean $\pm S D)$ \\
\hline Union & $0.868 \pm 0.043$ \\
\hline Nonunion & $0.849 \pm 0.056$ \\
\hline Lumbar lordosis angle in degrees* & $($ mean $\pm S D)$ \\
\hline Union & $20.8 \pm 7.9$ \\
\hline Nonunion & $25.2 \pm 8.8$ \\
\hline Lumbar inclination angle in degrees & (mean $\pm \mathrm{SD})$ \\
\hline Union & $83.1 \pm 6.3$ \\
\hline Nonunion & $75.1 \pm 8.6$ \\
\hline $\begin{array}{l}\text { * radiographs of } 31 \text { defects were } \\
p=0.0104 \\
\dagger \text { radiographs of } 93 \text { defects were ade } \\
\text { early and progressive stage defects in }\end{array}$ & $\begin{array}{l}\text { inadequate for measurement; } \\
\text { quate for measurement, and only } \\
\text { clusive; } p<0.0001\end{array}$ \\
\hline
\end{tabular}

III) included wedging of the affected vertebra measured as the lumbar index, the angle of lumbar lordosis, the angle of lumbar inclination and the presence of spinal bifida occulta in the affected vertebra (Fig. 3). ${ }^{21}$ Radiographs of 14 defects proved inadequate for the measurement of the angle of lumbar lordosis. The chronological age and the lumbar skeletal age were considered as systemic factors (Table IV).

The chi-squared test, the Mann-Whitney U test, the unpaired Student's $t$-test, the analysis of variance and Scheffe's $\mathrm{F}$ test for post hoc testing were used for statistical analysis, and $\mathrm{p}$ values of $<0.05$ were considered to indicate statistical significance. 

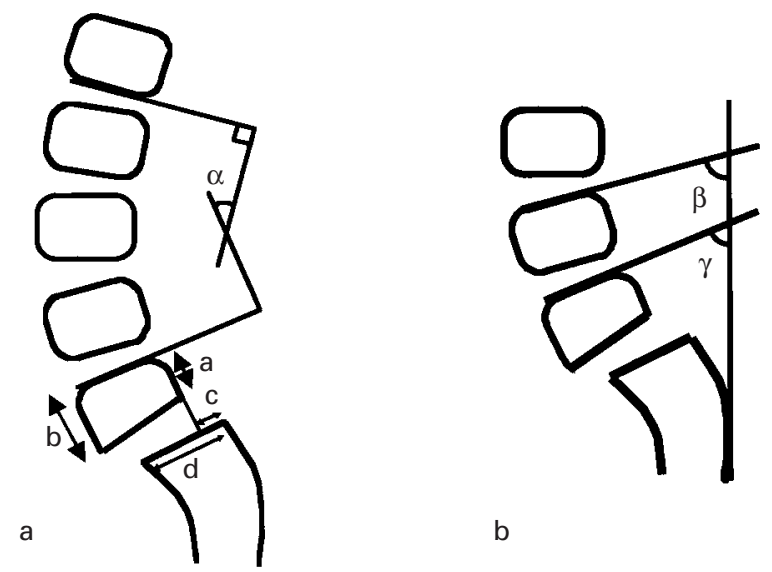

b

Fig. 3

Schematic drawings of measurement of the sagittal alignment of the lumbar spine on plain lateral radiographs. a) The lumbar index (L5) is determined by dividing distance a by distance b. The extent of slip is expressed as the percentage obtained by dividing c, the amount of displacement by $\mathrm{d}$ and multiplying the result by 100 . The lumbar lordosis angle is angle $\alpha$. b) The lumbar inclination angle is angle $\beta$ for $L 4$ and $\gamma$ for $L 5$.

\section{Results}

Comparison of the characteristics at the first presentation between patients with healed defects and those which remained are summarised in Tables II to IV. Since the vertebral level was one of the factors that significantly affected union of the pars defect, we also examined the union of defects by the vertebral level.

Pars interarticularis factors (local factors). As shown in Table II, the number of unions of early defects was significantly higher than that in the progressive or terminal stages $(p<0.0001)$. None of the latter united. The proportion of defects at L4 which achieved union was significantly higher
Table IV. Union of pars defects of the lumbar spine in children and systemic factors which may affect this process

\begin{tabular}{lc}
\hline Systemic factors & \\
\hline Chronological age & $($ mean \pm SD) in years \\
Union & $13.2 \pm 1.0$ \\
Nonunion & $13.6 \pm 2.2$ \\
Lumbar skeletal age & The number with union/total (\%) \\
Cartilaginous & $4 / 50(8.0)$ \\
Apophyseal & $31 / 139(22.3)$ \\
Epiphyseal & $5 / 50(10.0)$ \\
\hline
\end{tabular}

than that for defects at L5 $(\mathrm{p}<0.0001)$. The proportion of defects without contralateral defects or with contralateral early stage defects which achieved union was significantly higher than that for those with contralateral progressive or terminal stage defects $(p<0.001)$. Union occurred less often in the presence of a spondylolisthesis greater than $5 \%$ at the first presentation than in those without $(\mathrm{p}<0.01)$. Neither the angle nor the site of the early and progressive defects was significantly different between the union and nonunion groups. The occurrence of union of the defects of the pars in each subgroup is shown in Figure 4.

Lumbosacral factors. Neither the presence of spina bifida in the affected vertebra nor the degree of wedging of the fifth lumbar vertebra affected the union and nonunion groups (Table III). The angle of lumbar lordosis in the union group was significantly less than that in the nonunion group $(p<0.05)$. The angle of lumbar inclination of the affected vertebrae in the subgroups with early and progressive stage defects was significantly greater in those which united than in those which did not $(\mathrm{p}<0.0001)$.

Systemic factors. The chronological age of the patients when first seen did not differ between the two groups (Table IV). Bony union of the defects was achieved more often in the lumbar spine in the apophyseal stage $(22.3 \%)$ than in
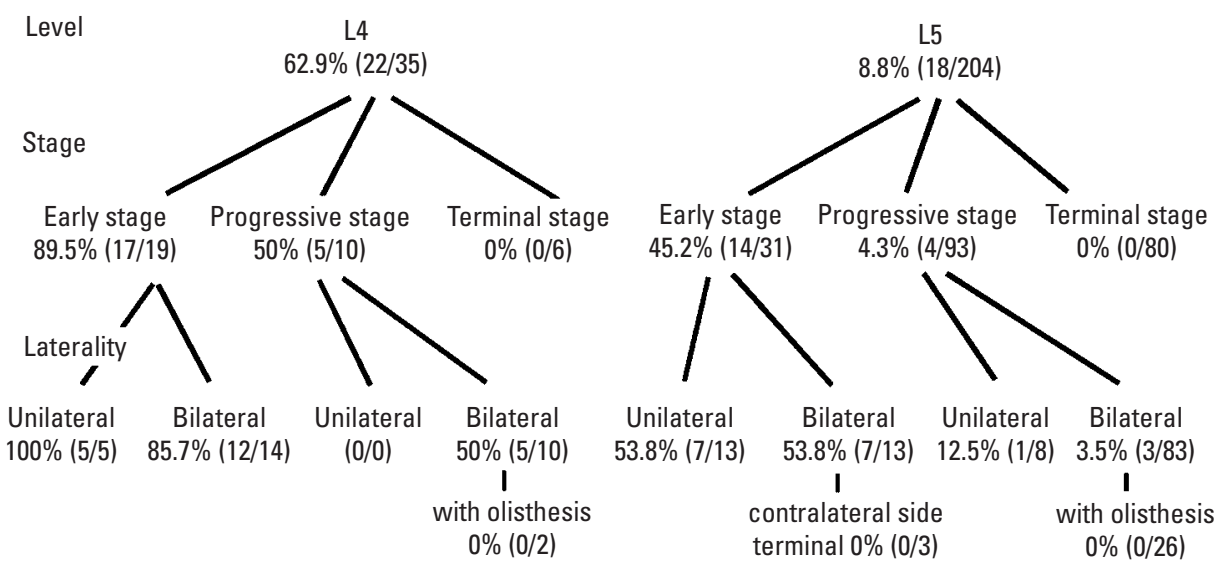

Fig. 4

The proportion of pars defects which achieved union, the skeletal level and the stage and the laterality of the defects. 
Table V. The number of the vertebrae in relation to lumbar skeletal age at the initial presentation and progression of spondylolisthesis for the 134 children with pars defects of the lumbar spine

\begin{tabular}{lllll}
\hline \multirow{2}{*}{ Number of vertebrae (\%) } & \multicolumn{2}{l}{ Lumbar skeletal age } & & \\
\cline { 2 - 4 } & Cartilaginous stage & Apophyseal stage & Epiphyseal stage & Total \\
\hline Without spondylolisthesis & $10(35.7)$ & $49(63.6)$ & $23(79.3)$ & $82(61.2)$ \\
With non-progressive spondylolisthesis & $8(28.6)$ & $15(19.7)$ & $6(20.7)$ & $29(21.6)$ \\
Development of spondylolisthesis & $9(32.1)$ & $10(13.0)$ & $0(0.0)$ & $19(14.2)$ \\
Increased spondylolisthesis & $1(3.6)$ & $3(3.9)$ & $0(0.0)$ & $4(3.0)$ \\
Total & $28(100)$ & $77(100)$ & $29(100)$ & $134(100)$ \\
\hline
\end{tabular}

Table VI. Numbers of unions of the pars defects, compared with lumbar skeletal age and spondylolisthesis for 239 pars defects of the lumbar spine in children

\begin{tabular}{|c|c|c|c|c|c|c|c|c|}
\hline & \multicolumn{6}{|c|}{ Lumbar skeletal age } & \multirow{2}{*}{\multicolumn{2}{|c|}{ Total }} \\
\hline & \multicolumn{2}{|c|}{ Cartilaginous stage } & \multicolumn{2}{|c|}{ Apophyseal stage } & \multicolumn{2}{|c|}{ Epiphyseal stage } & & \\
\hline & Union & Nonunion & Union & Nonunion & Union & Nonunion & Union & Nonunion \\
\hline Without spondylolisthesis & 3 & 12 & 29 & 57 & 5 & 33 & 37 & 102 \\
\hline With non-progressive spondylolisthesis & 1 & 15 & 1 & 28 & 0 & 12 & 2 & 55 \\
\hline Development of spondylolisthesis & 0 & 17 & 1 & 17 & 0 & 0 & 1 & 34 \\
\hline Increased spondylolisthesis & 0 & 2 & 0 & 6 & 0 & 0 & 0 & 8 \\
\hline Total & 4 & 46 & 31 & 108 & 5 & 45 & 40 & 199 \\
\hline
\end{tabular}

the cartilaginous stage $(8 \%)$, but the difference was not statistically significant.

Defects of the pars at L4. Among defects at L4, 17 of 19 in the early stage, and five of the ten in the progressive stage showed union; this difference was significant $(\mathrm{p}<0.05)$. We could not make a statistical comparison for defects in the early stage at L4 since only two of 19 did not show union.

The number of progressive stage defects was also small. There was no significant difference in the stage of the contralateral pars defect (early, 3 of 4; progressive, 2 of 6 ), the angle of lumbar lordosis (union, $21.4^{\circ}$; nonunion, $21.4^{\circ}$ ), the presence of spina bifida (with, 0 of 1 ; without, 5 of 9) or the presence of spondylolisthesis (with, 0 of 2; without, 5 of 8 ) between the two groups, except for the chronological age at the first presentation (union, 16.1 years; nonunion, 13.4 years; $\mathrm{p}<0.05$ ).

Defects of the pars at L5. Union was achieved in $8.8 \%$ of defects at L5 (Table II). The proportion of unions was significantly higher $(\mathrm{p}<0.0001)$ for early stage defects (14 of 31) than for progressive defects (4 of 93).

A significant difference was observed in the angle of the lumbar lordosis between patients with and without union (union, $16.7^{\circ}$; nonunion, $23.9^{\circ} ; \mathrm{p}<0.05$ ) among the early stage defects at L5. The distance of the defect from the posterior margin of the vertebra was greater in patients without union than in patients with union, but the difference was not significant (union, 0.427; nonunion, 0.544; $\mathrm{p}=$ 0.06). No significant differences between the two groups were observed with regard to chronological age at the first presentation (union, 13.8 years; nonunion, 14.9 years), the angle of lumbar inclination (union, $79.9^{\circ}$; nonunion, $76.2^{\circ}$ ), the presence of spina bifida (with, 4 of 5 ; without, 10 of 26 ), the presence of spondylolisthesis (with, 0 of 2 ; without, 14 of 29 ) or the angle of the defect (union, $10.2^{\circ}$; nonunion, $\left.17.7^{\circ}\right)$. None of three early stage defects with contralateral terminal stage defects at L5 showed union, while six of 13 defects without contralateral defects and eight of 15 defects with contralateral early or progressive stage defects healed. Although not significant, the status of the contralateral pars interarticularis tended to affect the union of the defects.

For patients with progressive stage defects at L5, the distance of the defect from the posterior margin of the vertebral body differed significantly between patients with and without union (union, 0.413; nonunion, 0.553; $\mathrm{p}<0.05$ ). Other factors including the chronological age at the first presentation (union, 13.2 years; nonunion, 13.6 years), the angle of lumbar lordosis (union, $13.5^{\circ}$; nonunion, $24.5^{\circ}$ ), the angle of lumbar inclination (union, $81.3^{\circ}$; nonunion, $77.0^{\circ}$ ), the presence of spina bifida (with, 1 of 22 ; without, 3 of 71), the presence of spondylolisthesis (with, 0 of 26; without, 4 of 67 ) and the angle of the defect (union, $17.9^{\circ}$; nonunion, $15.6^{\circ}$ ) showed no correlation with the occurrence of union. The number of unions of defects with contralateral early stage defects was significantly higher than those with contralateral progressive $(\mathrm{p}<0.01)$ or terminal stage $(\mathrm{p}<0.05)$ lesions (no defect, 1 of 8 ; early, 2 of 9; progressive, 1 of 55; terminal, 0 of 22).

Lumbar skeletal age and the development or progression of spondylolisthesis. The percentage of vertebra without spondylolisthesis at the time of follow-up increased in relation to the lumbar skeletal age at the initial presentation so that the risk of development of or increase in the degree of spondylolisthesis was greater in the immature lumbosacral spine $(\mathrm{p}<0.05$, Table $\mathrm{V})$. The ratio of union was significantly higher in defects where spondylolisthesis had not been observed at the first presentation or at the follow-up as compared to the other groups (Table VI). Only two defects healed when spondylolisthesis was noted at the first 
Table VII. List of the significant factors which affected union following conservative treatment of pars defects of the lumbar spine in 134 children

\begin{tabular}{ll}
\hline & Significant factors \\
\hline Local factors & Stage of the defect \\
& Vertebral level \\
& Stage of the contralateral defect \\
& Location of the defect (L5) \\
& Spondylolisthesis \\
Lumbosacral factors & Lumbar lordosis angle (L5 early stage) \\
& $\begin{array}{l}\text { Lumbar inclination angle (early and progressive } \\
\text { Stage) } \\
\text { Systemic factors }\end{array}$ \\
\hline
\end{tabular}

presentation without changing during follow-up, and none healed when the slip became worse.

\section{Discussion}

We attempted to identify the radiological variables which may influence the success of union of the defects using CT images to evaluate the pars interarticularis precisely. The stage of the defect was the most predominant predictor of a successful union. The reaction around the defect is one of the most important factors for union. However, movement in the pars interarticularis can also contribute. The instantaneous axis of rotation of the functional spinal units has been reported to shift cranially if degeneration of the intervertebral disc is present in adults. ${ }^{22}$ In adolescent patients with pars defects whose disc degeneration is minimal, this axis moved to the proximal vertebra in the presence of a progressive or terminal stage defect, it stayed in the disc space with an intact pars or early stage defect. ${ }^{20,23}$ The pars interarticularis is elongated if the defect is in the progressive or terminal stage, which is not the case in the pars with an early stage defect. ${ }^{6}$ The structural continuity of the pars in the early stage defect may keep the kinematics of the functional spinal unit normal and increase the incidence of bony union.

We also identified five other significant factors: 1) the vertebral level of the defect; 2) the degree of lumbar lordosis; 3$)$ slipping of the affected vertebra; 4) the site of the defect in the neural arch; and 5) the condition of the contralateral pars interarticularis. These factors influenced each other (Table VII).

The proportion of unions of defects at L4 was significantly higher than at L5. Difficulties in union of the defects in the early or progressive stage at L5 were significantly associated with the degree of lumbar inclination on radiographs taken in the standing position. A similar relationship was found between the angle of the lumbar lordosis and the difficulties in union of the early stage defects at L5. A study showed that the load on the facet joints was significantly greater at the L5-S1 facets than the L4-5 facets in the lumbar spine under axial compression; the load became greater as the lordotic curvature increased. ${ }^{24}$ The further load to the L5-S1 facet joints could cause separation of the pars defects which would interfere with bony union. Similar effects occur when the lumbar lordosis increases.
We also found that the site of the defect in the pars was important for the prediction of bony union, since healed defects in the progressive stage at L5 were significantly closer to the vertebral body than unhealed defects. Spina bifida and delayed development of the posterior structure of the lumbosacral spine have been advocated as aetiological and prognostic factors, but were not found to be significant in this study. ${ }^{25}$ The results seemed to be consistent with a previous report which showed that impairment of the development of the posterior structures was secondary to the occurrence of the defects. ${ }^{26}$

Although the defects in the cartilaginous stage of the lumbar spine might have a higher potential for union, the proportion of unions was lower than that for defects in the apophyseal stage. A clinical study on spondylolisthesis showed that a slip occurred in the cartilaginous and the apophyseal stage, but not in the epiphyseal stage, and occurred at the vertebral endplate, as demonstrated by MRI. ${ }^{14,27}$ These findings were supported by a series of experimental studies. Biomechanical investigation showed that the vertebral endplate is the weakest link of the functional spinal unit in the spine of the immature calf, and that the strength of the growth plate against anterior shearing forces depends on skeletal maturity. ${ }^{15,28,29}$ A histological study using a rat model showed that the disruption of the growth plate occurred after posterior destabilisation. ${ }^{30}$ The higher occurrence of spondylolisthesis seemed to reflect the lower rate of the union of the defects of the pars in the lumbar spine in the cartilaginous stage.

Our treatment of early stage defects at L4 appeared to be adequate for achieving union of the defects since 17 of 19 of this stage healed. The outcome, however, was only fair for progressive stage defects at L4 and early stage defects at L5. The likelihood of union of the progressive defects at L5 was less than $5 \%$. Since early or progressive stage defects and defects in the cartilaginous stage of the lumbar spine may still have a potential for bony union, rigid immobilisation with decreased lumbar lordosis or other methods of treatment should be considered.

Early detection of the defects will also improve the outcome. Quantitative single-photon emission CT or MRI can provide important information for early detection or union of the pars defect, but progress of the union or morphological changes of the defect cannot be evaluated by these means. 31,32

No benefits in any form have been received or will be received from a commercial party related directly or indirectly to the subject of this article.

\section{References}

1. Wiltse LL, Widell EH Jr, Jackson DW. Fatigue fracture: the basic lesion is isthmic spondylolisthesis. J Bone Joint Surg [Am] 1975;57-A:17-22.

2. Farfan HF, Osteria V, Lamy C. The mechanical etiology of spondylolysis and spondylolisthesis. Clin Orthop 1976;117;40-55.

3. Fredrickson BE, Baker D, McHolick WJ, Yuan HA, Lubicky JP. The natural history of spondylolysis and spondylolisthesis. J Bone Joint Surg [Am] 1984;66-A: 699-707.

4. Jackson DW, Wiltse LL, Cirincoine RJ. Spondylolysis in the female gymnast. Clin Orthop 1976;117:68-73. 
5. Merbs CE. Incomplete spondylolysis and healing: study of ancient Canadian Eskimo skeletons. Spine 1995;20:2328-34.

6. Morita T, Ikata T, Katoh S, Miyake R. Lumbar spondylolysis in children and adolescents. J Bone Joint Surg [Br] 1995;77-B:620-5.

7. O'Neill DB, Micheli LJ. Postoperative radiographic evidence for fatigue fracture as the etiology in spondylolysis. Spine 1989;14:1432-55.

8. Rosenberg NJ, Bargar WL, Friedman B. The incidence of spondylolysis and spondylolisthesis in nonambulatory patients. Spine 1981;6:35-8.

9. Rowe GG, Roche MB. The etiology of the separate neutral arch. J Bone Joint Surg [Am] 1953;35-A:102-10.

10. Sagi HC, Jarvis JG, Uhthoff HK. Histomorphic analysis of the development of the pars interarticularis and its association with isthmic spondylolysis. Spine 1998;23:1635-9.

11. Blanda J, Bethem D, Moats W, Lew M. Defects of pars interarticularis in athletes: a protocol for nonoperative treatment. J Spinal Disord 1993;6:406-11.

12. Katoh S, Ikata T, Morita T, et al. Lumbar spinal disorders in young athletes: outcome of conservative treatment for spondylolysis and end-plate lesions. In: Abe 0 , Inokuchi K, Takasaki K, eds. XXX World Congress of the International College of Surgeons. Vol. 2. Kyoto, Japan: Monduzzi Editore, 1996:1299-302.

13. Muschik M, Hahnel H, Robinson PN, Perka C, Muschik C. Competitive sports and the progression of spondylolisthesis. J Pediatr Orthop 1996;16:364-9.

14. Ikata T, Miyake R, Katoh S, Morita T, Murase M. Pathogenesis of sports-related spondylolisthesis in adolescents: radiographic and magnetic resonance imaging study. Am J Sports Med 1996;24:94-8

15. Konz RKJ, Goel VK, Grobler LJ, et al. The pathomechanism of spondylolytic spondylolisthesis in immature primate lumbar spines in vitro and finite element assessments. Spine 2001;26:E38-49.

16. Steiner MR, Micheli LJ. Treatment of symptomatic spondylolysis and spondylolisthesis with the modified Boston brace. Spine 1985;10:937-43.

17. Cyron BM, Hutton WC. The fatigue strength of the lumbar neural arch in spondylolysis. J Bone Joint Surg [Br] 1978;60-B:234-8.

18. Krenz J, Troup JD. The structure of the pars interarticularis of the lower lumbar vertebrae and its relation to the etiology of spondylolysis, with a report of a healing fracture in the neural arch of a fourth lumbar vertebra. J Bone Joint Surg [Br] 1973;55-B: 735-41.
19. Lafferty JF, Winter WG, Gambaro SA. Fatigue characteristics of posterior elements of vertebrae. J Bone Joint Surg [Am] 1977;59-A:154-8.

20. Sakamaki T, Katoh S, Sairyo K. Normal and spondylolytic pediatric spine movements with reference to instantaneous axis of rotation. Spine 2002;27:141-5.

21. Wiltse LL, Winter RB. Terminology and measurement of spondylolisthesis. J Bone Joint Surg [Am] 1983;65-A:68-72.

22. Rolander SD. Motion of the lumbar spine with special reference to the stabilizing effect of posterior fusion: an experimental study on autopsy specimens. Acta Orthop Scand 1966;Suppl 90:1-144.

23. Szypryt EP, Twining P, Mulholland RC, Worthington BS. The prevalence of disc degeneration associated with neural arch defects of the lumbar spine assessed by magnetic resonance imaging. Spine 1989;14:977-81.

24. Shirazi-AdI A, Parnianpour M. Role of posture in mechanics of the lumbar spine in compression. J Spinal Disord 1996;9:277-86.

25. Einstein S. Spondylolysis: a skeletal investigation of two population groups. J Bone Joint Surg [Br] 1978;60-B:488-94.

26. Miyake R, Ikata T, Katoh S, Morita T. Morphological analysis of the facet joint in the immature lumbosacral spine with special reference to spondylolysis. Spine 1996; 21:783-9.

27. Sairyo K, Katoh S, Ikata T, et al. Development of spondylolytic olisthesis in adolescents. Spine J 2001;1:171-5.

28. Sairyo K, Goel VK, Grobler LJ, Ikata T, Katoh S. The pathomechanism of isthmic lumbar spondylolisthesis: a biomechanical study in immature calf spines. Spine 1998 23:1442-6.

29. Kajiura K, Katoh S, Sairyo K, et al. Slippage mechanism of pediatric spondylolysis: biochemical study using immature calf spines. Spine 2001;26:2208-12.

30. Sakamaki T, Sairyo K, Katoh S, et al. The pathogenesis of slippage and deformity in the pediatric lumbar spine: a radiographic and histologic study using a new rat in vivo model. Spine 2003;28:645-50.

31. Anderson K, Sarwark JF, Conway JJ, Logue ES, Schafer MF. Quantitative assessment with SPECT imaging of stress injuries of the pars interarticularis and response to bracing. J Pediatr Orthop 2000;20:28-33.

32. Yamane T, Yoshida T, Mimatsu K. Early diagnosis of lumbar spondylolysis by MRI J Bone Joint Surg [Br] 1993;75-B:764-8. 